Article

\title{
Polypyrrole Nanotubes and Their Carbonized Analogs: Synthesis, Characterization, Gas Sensing Properties
}

\author{
Jitka Kopecká ${ }^{1}$, Miroslav Mrlík ${ }^{2}$, Robert Olejník ${ }^{2}$, Dušan Kopecký ${ }^{1, *}$, Martin Vrňata ${ }^{1}$, \\ Jan Prokeš ${ }^{3}$, Patrycja Bober ${ }^{4}$, Zuzana Morávková ${ }^{4}$, Miroslava Trchová ${ }^{4}$ and Jaroslav Stejskal ${ }^{4}$ \\ 1 Department of Physics and Measurements, University of Chemistry and Technology Prague, \\ Prague 6 CZ-166 28, Czech Republic; Jitka.Kopecka@vscht.cz (J.K.); martin.vrnata@vscht.cz (M.V.) \\ 2 Centre of Polymer Systems, University Institute, Tomas Bata University in Zlin, Zlin CZ-760 01, \\ Czech Republic; mrlik@ft.utb.cz (M.M.); olejnik@ft.utb.cz (R.O.) \\ 3 Faculty of Mathematics and Physics, Charles University in Prague, Prague 8 CZ-180 00, Czech Republic; \\ jprokes@semi.mff.cuni.cz \\ 4 Institute of Macromolecular Chemistry, Academy of Sciences of the Czech Republic, Prague 6 CZ-162 06, \\ Czech Republic; bober@imc.cas.cz (P.B.); moravkova@imc.cas.cz (Z.M.); trchova@imc.cas.cz (M.T.); \\ stejskal@imc.cas.cz (J.S.) \\ * Correspondence: kopeckyd@vscht.cz; Tel.: +420-220-443-351
}

Academic Editor: W. Rudolf Seitz

Received: 5 September 2016; Accepted: 8 November 2016; Published: 15 November 2016

\begin{abstract}
Polypyrrole (PPy) in globular form and as nanotubes were prepared by the oxidation of pyrrole with iron(III) chloride in the absence and presence of methyl orange, respectively. They were subsequently converted to nitrogen-containing carbons at $650{ }^{\circ} \mathrm{C}$ in an inert atmosphere. The course of carbonization was followed by thermogravimetric analysis and the accompanying changes in molecular structure by Fourier Transform Infrared and Raman spectroscopies. Both the original and carbonized materials have been tested in sensing of polar and non-polar organic vapors. The resistivity of sensing element using globular PPy was too high and only nanotubular PPy could be used. The sensitivity of the PPy nanotubes to ethanol vapors was nearly on the same level as that of their carbonized analogs (i.e., $~ 18 \%$ and $24 \%$, respectively). Surprisingly, there was a high sensitivity of PPy nanotubes to the $n$-heptane vapors $(\sim 110 \%)$, while that of their carbonized analog remained at $\sim 20 \%$. The recovery process was significantly faster for carbonized PPy nanotubes (in order of seconds) compared with $10 \mathrm{~s}$ of seconds for original nanotubes, respectively, due to higher specific surface area after carbonization.
\end{abstract}

Keywords: polypyrrole nanotube; carbon nanotube; carbonization; functionalized nanotube; heptane detection

\section{Introduction}

Since carbon nanotubes (CNTs) appeared to be very attractive for volatile organic compounds detection, many research groups focused on the development of the various sensors [1-7]. It was observed that especially defects and/or impurities, such as heteroatoms, present in nanotubes are responsible for their detection ability, since they modify generally low chemical interaction of CNTs with gas or vapor analytes $[2,8]$. The neat CNTs are able to detect only molecules with electron-donating (e.g., $\mathrm{NH}_{3}$ ) or electron-accepting (e.g., $\mathrm{NO}_{2}$ ) properties, but, in general, for the detection of such weakly absorbed molecules on the surface their change of the resistance (i.e., sensitivity) is small [9]. On the contrary, the functionalized nanotubes exhibit higher molecular reactivity, therefore the development of new carbonaceous materials with controlled morphology is a promising research direction in sensing 
applications [10-14]. Polypyrrole (PPy) is also known to be a promising material for gas sensors detecting vapors of organic solvents [15]. Another interesting aspect is represented by the possibility to study properties of PPy-based sensors by impedance spectroscopy [16].

Conducting polymers, such as PPy [17-19], have been shown to produce nitrogen-containing carbons when exposed to temperature above $600{ }^{\circ} \mathrm{C}$ in an inert atmosphere. It is important to stress that the morphology is retained during this process but the specific surface area is likely to increase. An extensive review concerning the carbonization of these two polymers has recently been published [20].

Polypyrrole is usually prepared by the oxidation of pyrrole with iron(III) salts [21,22] or ammonium peroxydisulfate [23]. Polypyrrole typically has a globular morphology [21]. When prepared in the presence of so-called structure-guiding agents, such as methyl orange, PPy is obtained as nanotubes [19,24-29]. It is of interest if the difference in nano-scale morphology, globular or nanotubular, would be reflected in sensing applications.

In present study, globular and nanotubular PPy has been prepared and subsequently converted to nitrogen-containing CNTs by exposure to elevated temperature in an inert atmosphere. The vapor response of both the original and carbonized PPy was investigated for two organic solvents, polar ethanol and non-polar $n$-heptane, by using evaluation of resistance changes.

\section{Materials and Methods}

\subsection{Preparation}

Globular PPy was prepared by chemical polymerization of pyrrole monomer with iron(III) chloride hexahydrate at equimolar ratio in water. Molar concentrations of both reactants were $422 \mathrm{mM}$, total volume of reaction mixture was $379 \mathrm{~mL}$. The stirred reaction mixture was kept at $5^{\circ} \mathrm{C}$ for $24 \mathrm{~h}$. The precipitated PPy was separated by filtration, rinsed with water and acetone, and dried at $40^{\circ} \mathrm{C}$ in vacuo.

Polypyrrole nanotubes were synthesized in similar manner in the presence of structure-guiding additive, methyl orange, and sodium 4-[4-(dimethylamino)phenylazo]-benzenesulfonate. $200 \mathrm{~mL}$ of $2.5 \mathrm{mM}$ solution of methyl orange in distilled water and $700 \mu \mathrm{L}$ of pyrrole were mixed. Then solution of $10 \mathrm{mmol}$ iron(III) chloride hexahydrate dissolved in $23 \mathrm{~mL}$ distilled water was added drop-wise during two hours. Both solutions were cooled to $5{ }^{\circ} \mathrm{C}$ before mixing and kept at this temperature afterwards. Molar concentrations of reactants thus were $45 \mathrm{mM}$ pyrrole, $45 \mathrm{mM}$ iron(III) chloride hexahydrate, and $2.2 \mathrm{mM}$ methyl orange. After $24 \mathrm{~h}$, precipitated PPy nanotubes were isolated by filtration, and purified by Soxhlet extraction using acetone until the extract was colorless. Polypyrrole nanotubes were dried as above. Both samples were converted to PPy bases [30] by overnight immersion in excess of $1 \mathrm{M}$ ammonium hydroxide, rinsed with acetone, and dried.

\subsection{Carbonization of Polypyrrole}

Thermogravimetric analysis was used at first as an analytical tool of PPy carbonization. This was performed in $50 \mathrm{~cm}^{3} \cdot \mathrm{min}^{-1}$ nitrogen flow at a heating rate of $10{ }^{\circ} \mathrm{C} \cdot \mathrm{min}^{-1}$ with a TGA 7 Thermogravimetric Analyzer (Perkin Elmer, Waltham, MA, USA). A comparative experiment in air has also been done.

In a preparative carbonization, $5 \mathrm{~g}$ of PPy nanotubes or globular PPy bases were heated in an inert nitrogen atmosphere to $650{ }^{\circ} \mathrm{C}$ in an electric oven. The selection of this particular temperature was made according previous experiments on polyaniline and PPy. In case of polyaniline it follows from the evolution of the infrared and Raman spectra that after carbonization at $650{ }^{\circ} \mathrm{C}$, the $\mathrm{G}$ and $\mathrm{D}$ bands characteristic of a carbon material are well developed and the residue of the sample is close to $60 \mathrm{wt} \%$. It has been proven also for nanotubular PPy derived carbon nanotubes [20]. When the carbonization temperature was lower, the carbonization was not complete. At higher temperatures, the yield of carbonized product is substantially reduced. 
The heating was switched on, and the temperature increased at $10^{\circ} \mathrm{C} \cdot \mathrm{min}^{-1}$ rate. After the target temperature was reached, the heating was switched off, and the residue was left to cool down in the flowing nitrogen stream.

\subsection{Characterization}

Infrared spectra in the range of $400-4000 \mathrm{~cm}^{-1}$ were recorded at 64 scans per spectrum at $2 \mathrm{~cm}^{-1}$ resolution using a fully computerized NEXUS 870 FTIR Spectrometer (Thermo Fisher Scientific, Waltham, MA, USA) with DTGS TEC detector (Thermo Fisher Scientific). Samples were dispersed in potassium bromide and compressed into pellets. Raman spectra excited with a diode $785 \mathrm{~nm}$ laser were collected on a Renishaw inVia Reflex Raman spectroscope. A research-grade Leica DM LM microscope (Leica Microsystems, Wetzlar, Germany) with an objective magnification $50 \times$ was used to focus the laser beam. The scattered light was analyzed by the spectrograph with a holographic grating 1200 lines $\mathrm{mm}^{-1}$. A Peltier-effect cooled CCD detector $(576 \times 384$ pixels) registered the dispersed light. To avoid degradation of the samples by the laser beam, a reduced beam power was always used. Transmission electron microscope (TEM) JEOL JEM 2000 FX (JEOL, Tokyo, Japan) and scanning electron microscope (SEM) JEOL 6400 (JEOL, Tokyo, Japan) were used to assess the morphology. Specific surface area was determined by nitrogen adsorption using a Gemini VII 2390 Analyzer (Micrometrics Instruments Inc., Norcross, GA, USA).

Room temperature conductivity of PPy nanotubes was determined on pellets compressed at $700 \mathrm{MPa}$ by a four-point method in the van der Pauw arrangement using a Keithley 220 Programmable Current Source, a Keithley 2010 Multimeter (Keithley Instruments, Solon, OH, USA) as a voltmeter and a Keithley 705 Scanner (Keithley Instruments) equipped with a Keithley 7052 Matrix Card (Keithley Instruments). The conductivity of globular PPy and carbonized PPy was estimated on powders placed between two conducting pistons by two-probe method with applied pressure of ca. $23 \mathrm{kPa}$ and using a Keithley 6517 electrometer (Keithley Instruments).

\subsection{Vapor Response}

Polypyrrole nanotubes, both original and carbonized form, were dispersed in $50 \mathrm{~mL}$ of deionized water containing $0.1 \mathrm{M}$ of sodium dodecyl sulfate (SDS) surfactant (Sigma Aldrich, St. Louis, MO, USA) and 0.14 M of 1-pentanol (Sigma Aldrich), respectively. The concentration of nanotubes in the suspension was $0.3 \mathrm{wt} \%$. The suspension was homogenized in an ultrasonic apparatus (UZ Sonopuls HD 2070, Bandelin, Germany) for $5 \mathrm{~min}$ at ca. $50^{\circ} \mathrm{C}$. Polypyrrole nanotube networks were prepared by vacuum filtration of suspension thought nonwoven polyurethane membrane, composed of polyurethane straight fibers with average diameter $0.14 \pm 0.09 \mu \mathrm{m}$. The fibers' surface was smooth and the main pore size was around $0.2 \mu \mathrm{m}$. Thus, prepared network on polyurethane support was rinsed several times with deionized water and methanol. After drying, this composite structure was tested as a layer sensitive to volatile organic compounds when exposed to the vapors of $n$-heptane and ethanol (having nearly the same vapor pressure at room temperature but with different polarity). For sensitivity testing, laboratory air was used as the reference gas. Aqueous suspensions of globular PPy in $0.4 \mathrm{wt} \%$ concentration were similarly prepared and processed.

The stripes $5 \times 20 \mathrm{~mm}^{2}$ made of active components deposited on polyurethane supports were placed on a planar holder with copper electrodes fixed on both sides of the stripe by a screw mechanism. Time-dependent electrical resistance was measured along the specimen length by the two-point technique using a multimeter Keithley 6517B (Keithley Instruments) during adsorption (analyte-on phase) and desorption (analyte-off phase). The holder with the specimen was transferred into an air-tight conical flask containing saturated vapors of the respective solvent at atmospheric pressure and $25^{\circ} \mathrm{C}$. Under these conditions, the saturated vapor of ethanol has a concentration of $7.7 \mathrm{vol} \%$ and the corresponding value for $n$-heptane is $6.0 \mathrm{vol} \%$. After $6 \mathrm{~min}$ of measurement the holder was removed from the flask and, for the next $6 \mathrm{~min}$, the sample resistance was measured in laboratory air in the desorption mode until steady state. The sensitivity of sensors, a relative change in 
resistivity is defined as $S[\%]=\left(R_{\mathrm{g}}-R_{\mathrm{a}}\right) / R_{\mathrm{a}} \times 100$, where $R_{\mathrm{a}}$ is the resistance in air under laboratory conditions and $R_{\mathrm{g}}$ is the resistance of the specimen exposed to organic vapor.

\section{Results and Discussion}

The classical preparation of PPy yields a product with globular morphology [21] (Figure 1a left). Its carbonization proved that the morphology is retained when this process is carried out in an inert atmosphere (Figure 1a right). The introduction of methyl orange to the reaction mixture results in a dramatic change in polymer morphology, and PPy nanotubes are obtained instead (Figure $1 \mathrm{~b}$ left). The cavity inside the nanotubes is demonstrated by using transmission electron microscopy (Figure 2).
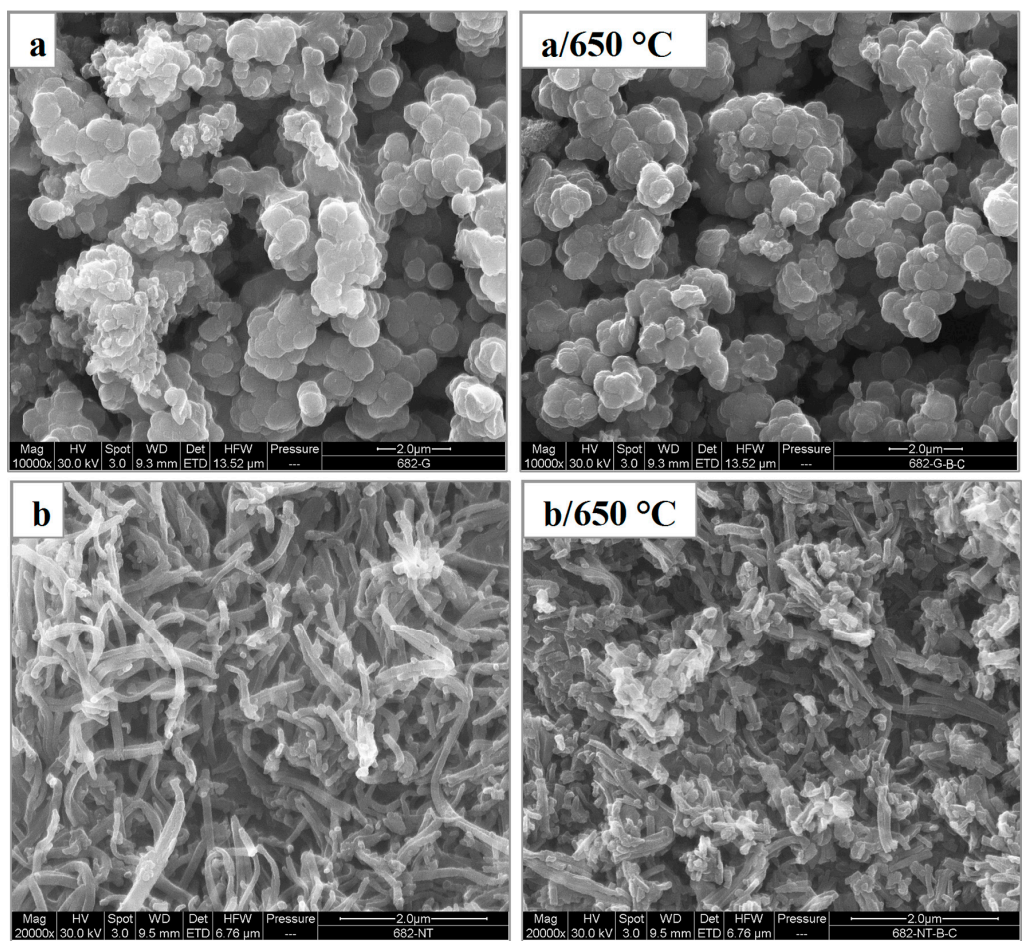

Figure 1. Scanning electron micrographs of (a) original globular polypyrrole and (b) polypyrrole nanotubes. They are depicted before- (left column) and after- carbonization at $650{ }^{\circ} \mathrm{C}$ (right column).

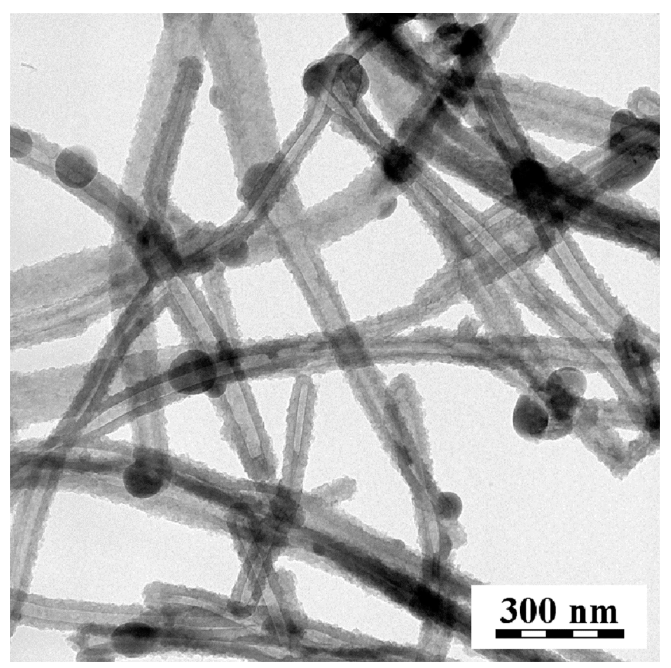

Figure 2. Illustration of nanotubular morphology by transmission electron microscopy. 
The nanotubular structure is damaged but not destroyed after carbonization (Figure $1 \mathrm{~b}$ right). The shrinkage is the consequence of the loss of mass during the exposure to elevated temperature (Figure 3).
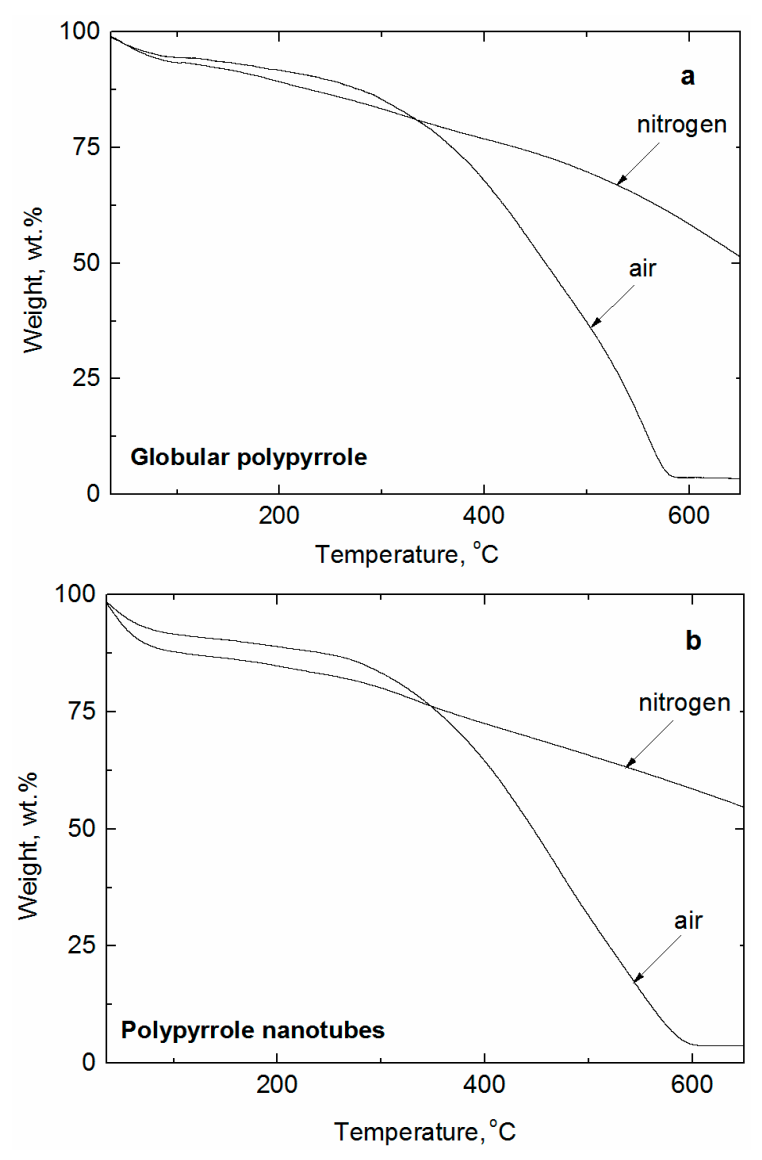

Figure 3. Thermogravimetric analysis of (a) globular polypyrrole and (b) polypyrrole nanotubes in air and in nitrogen.

The conductivity of PPy obtained by oxidative polymerization of pyrrole with iron(III) chloride is usually around units $\mathrm{S} \cdot \mathrm{cm}^{-1}$ [31,32]. In the presented case, the conductivity of globular PPy was of the order of $10^{-2} \mathrm{~S} \cdot \mathrm{cm}^{-1}$ (Table 1). By changing the morphology from globules to nanotubes, the conductivity increased to $60 \mathrm{~S} \cdot \mathrm{cm}^{-1}$. After the deprotonation with ammonium hydroxide the conductivity decreases by several orders of magnitude due to conversion of conducting PPy to less conducting PPy base. Polypyrrole bases have originally been intended for the application in electrorheology [33-35] but, for that purpose, the conductivity of the nanotubular form was too high. For that reason, the samples have been tested in the present study for sensing properties, where the level of conductivity is suitable.

Table 1. Conductivity and specific surface area of globular and nanotubular PPy salts, bases, and their carbonized analogs.

\begin{tabular}{ccccccc}
\hline \multirow{2}{*}{ Sample } & \multicolumn{3}{c}{ Conductivity $\left(\mathbf{S} \cdot \mathbf{c m}^{-\mathbf{1}}\right)$} & \multicolumn{3}{c}{ Specific Surface Area $\left(\mathbf{m}^{\mathbf{2}} \cdot \mathbf{g}^{-\mathbf{1}}\right)$} \\
\cline { 2 - 6 } & Salt & Base & Carbonized Base & Salt & Base & Carbonized Base \\
\hline PPy nanotubes & $60^{\text {a }}$ & $6.7 \times 10^{-2}$ a & $6.7 \times 10^{-6}$ & 75 & 63 & 211 \\
Globular PPy & 0.011 & $3.4 \times 10^{-5}$ & $1.4 \times 10^{-7}$ & 26 & 25 & 150 \\
\hline
\end{tabular}

a Measured on pellets compressed at 530 MPa pressure. Pellets could not be prepared from other samples. Their conductivity was estimated in a powdered state. Such conductivities are usually one to two orders of magnitude lower compared with those of the pellets. 


\subsection{Analytical Carbonization}

To get a deeper insight into the process of carbonization, thermogravimetric analysis was performed both in air and nitrogen atmosphere. The analysis in air illustrates the complete destruction of PPy between $550{ }^{\circ} \mathrm{C}$ and $600{ }^{\circ} \mathrm{C}$ (Figure 3a). There is no significant difference in the thermal stability between globular and nanotubular forms of PPy. A residue of $\approx 5 \mathrm{wt} \%$ is most likely represented by iron oxides produced from the oxidant, iron(III) chloride.

In inert nitrogen atmosphere, however, the residue is in both cases above $50 \mathrm{wt} \%$ at $650{ }^{\circ} \mathrm{C}$. Also here, there is no substantial difference in the stability of globular and nanotubular PPy (Figure $3 b$ ). This is logical, because the thermal stability is established by molecular, rather than supramolecular, structure.

\subsection{FTIR Spectroscopy}

\subsubsection{Polypyrrole Bases}

Infrared spectra of granular and nanotubular PPy bases (Figure 4) are close to each other and correspond well to the spectra of PPy bases described in the literature [23]. We observe a broad absorption band at wavenumbers above $2000 \mathrm{~cm}^{-1}$, and the band at about $1700 \mathrm{~cm}^{-1}$ which corresponds to the presence of a carbonyl group formed by the nucleophilic attack of pyrrole by water during the preparation $[21,23]$. The band at $1572 \mathrm{~cm}^{-1}$ is assigned to $C-C$ stretching vibrations in the pyrrole ring, the band at $1475 \mathrm{~cm}^{-1}$ to $\mathrm{C}-\mathrm{N}$ stretching vibration in the ring. A broad band attributed to $\mathrm{C}-\mathrm{H}$ or $\mathrm{C}-\mathrm{N}$ in-plane deformation modes with a maximum at $1300 \mathrm{~cm}^{-1}$ is well detected in the spectra. In the region of the $\mathrm{C}-\mathrm{H}$ and $\mathrm{N}-\mathrm{H}$ in-plane deformation vibrations from 1250 to $1000 \mathrm{~cm}^{-1}$, we observe a maximum at $1170 \mathrm{~cm}^{-1}$ in the spectra of PPy base. The bands corresponding to the $\mathrm{C}-\mathrm{H}$ and $\mathrm{N}-\mathrm{H}$ in-plane deformation vibrations are situated at $1030 \mathrm{~cm}^{-1}$ and to C-C out-of-plane ring-deformation vibrations at $965 \mathrm{~cm}^{-1}$. The $\mathrm{C}-\mathrm{H}$ out-of-plane deformation vibrations of the pyrrole ring (at about $907 \mathrm{~cm}^{-1}$ ) and of the $\mathrm{C}-\mathrm{H}$ out-of-plane ring deformations (at about $776 \mathrm{~cm}^{-1}$ ) are present in the spectra of the PPy base.

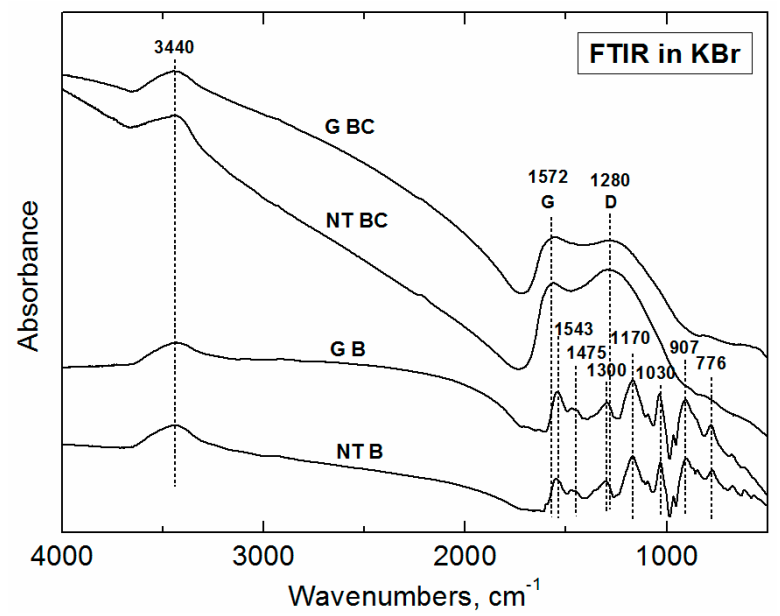

Figure 4. FTIR spectra of original globular $(\mathrm{G})$ and nanotubular (NT) polypyrrole bases before (B) and after (BC) carbonization.

\subsubsection{Carbonized Materials}

In the FTIR spectra of carbonized PPy bases, we observe a local maximum at $1572 \mathrm{~cm}^{-1}$, and a broad band with a maximum at about $1280 \mathrm{~cm}^{-1}$. The first band emerged from the $\mathrm{C}-\mathrm{C}$ stretching vibrations in the pyrrole ring, the second from the $\mathrm{C}-\mathrm{N}$ in-plane deformation modes. The shape of the spectra is close to that of the spectra of a carbon-like material with the Raman-active D and G bands, 
which are usually inactive in FTIR spectra. In disordered samples, however, they become IR-active because of symmetry-breaking of the carbon network, but they are rather weak and the spectra are flat and almost featureless.

\subsection{Raman Spectroscopy}

\subsubsection{Polypyrrole Bases}

Raman spectroscopy is well suited to characterize the progress of carbonization (Figure 5). Raman spectra of powdered samples have been recorded with excitation wavelength $785 \mathrm{~nm}$. The spectra of globular and nanotubular PPy bases differ in elevated intensity and narrower shape of the band located at $930 \mathrm{~cm}^{-1}$ (C-H out-of-plane deformation vibrations of dication-bearing unit [36]), the presence of band at $1555 \mathrm{~cm}^{-1}$, and a shoulder around $1415 \mathrm{~cm}^{-1}$ in the case of nanotubular PPy. The PPy base bands are located at $1615 \mathrm{~cm}^{-1}(C=C$ stretching in the pyrrole ring), $1495 \mathrm{~cm}^{-1}\left(\mathrm{C}=\mathrm{N}\right.$ stretching vibrations in the pyrrole ring), $1390 \mathrm{~cm}^{-1}(\mathrm{C}-\mathrm{H}$ and $\mathrm{N}-\mathrm{H}$ bending, $1330 \mathrm{~cm}^{-1}$ (C-C stretching of neutral units), $1245 \mathrm{~cm}^{-1}$ (antisymmetric C-H bending), $1045 \mathrm{~cm}^{-1}$ (in-plane ring-deformation vibrations) with a shoulder at $1090 \mathrm{~cm}^{-1}(\mathrm{C}-\mathrm{H}, \mathrm{N}-\mathrm{H}$ and out-of-plane ring-deformation vibrations), $980 \mathrm{~cm}^{-1}$ (C-C deformation vibrations in neutral rings), $687 \mathrm{~cm}^{-1}$, and $617 \mathrm{~cm}^{-1}$ (ring-deformation vibrations).

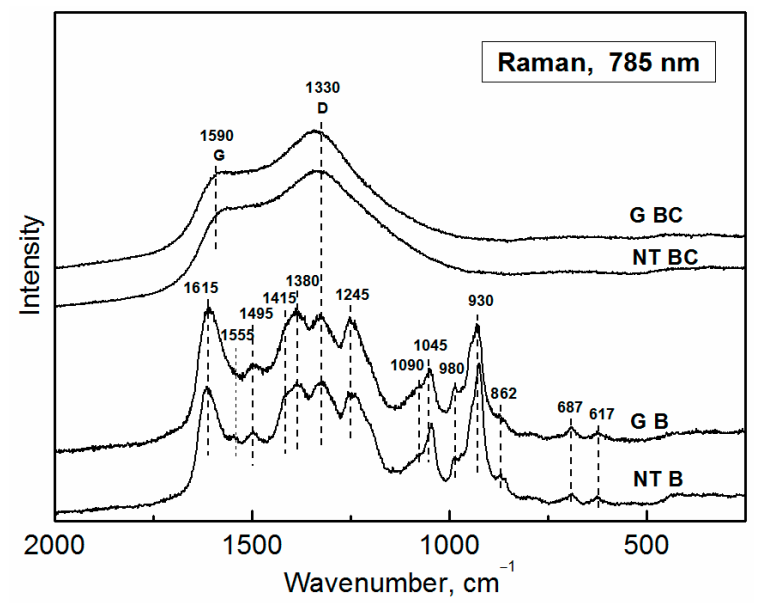

Figure 5. Raman spectra of original globular (G) polypyrrole bases and polypyrrole nanotubes (NT) before (B) and after carbonization (BC).

\subsubsection{Carbonized Materials}

In the Raman spectra of carbonized PPy the band at $1590 \mathrm{~cm}^{-1}$ (emerged from the $\mathrm{C}=\mathrm{C}$ stretching vibrations of the pyrrole ring) and the broad band centered at $1330 \mathrm{~cm}^{-1}$ (emerged from the $\mathrm{C}-\mathrm{C}$ stretching vibrations of the pyrrole ring) can be observed. These bands can be considered as G-band ("graphitic" band, $\mathrm{C}=\mathrm{C}$ stretching vibrations of any pair of $\mathrm{sp}^{2}$ sites) and D-band ("disorder" band, breathing of aromatic rings activated by any defect including a heteroatom), bands defined for graphitic material [37] and proved to be usable for nitrogen-doped graphitic material. The spectrum corresponds to a disordered nitrogen-containing graphitic material.

\subsection{Vapor Response}

In the case of globular PPy samples, the resistivity of the prepared materials was too high, thus the vapor response properties of corresponding sensors were not measurable. The response properties of both PPy nanotubes as well as their carbonized forms were obtained (Figures 6 and 7). When detecting ethanol vapors (Figure 6), the sensitivity (i.e., a relative increase in resistance) of both nanotubular samples differs only slightly (i.e., 18\% for non-carbonized PPy and 24\% for a carbonized analog). 
When detecting $n$-heptane (Figure 7 ), the significantly better sensitivity of $110 \%$ was determined for the original PPy nanotubular base, while the carbonized ones exhibit only a $20 \%$ response. The high sensitivity to $n$-heptane is remarkable because typical values reported in the literature for detection of alkanes are of the order of units of a percent [38]. We can speculate that the high sensitivity of as-synthesized of PPy to $n$-heptane is connected with the reduction of humidity level in the sample and consequent increase in its resistivity. Another interpretation of this phenomenon can be made according to basic theory of sensing mechanisms on conducting polymers [39-42]: Doping and undoping play key roles in the sensing mechanism of conducting polymer based sensors. Their doping level can be altered by transferring electrons from or to the sensitive layer. All $\pi$ - or $\sigma$-electron donating gases can be detected. Our analyte ( $n$-heptane) probably acts as an $\sigma$-electron donor.

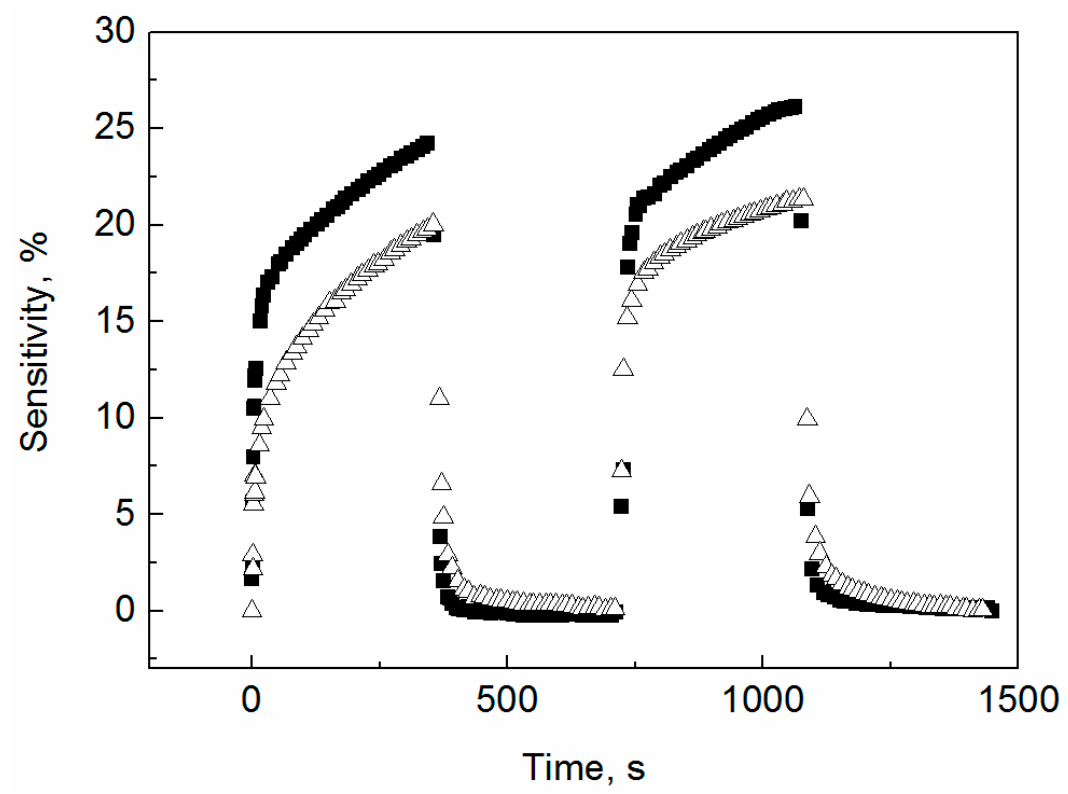

Figure 6. The response profile during two adsorption/desorption cycles in the presence of ethanol $(7.7 \mathrm{vol} \%)$ for $(\triangle)$ polypyrrole nanotubes and $(\mathbf{\square})$ carbonized polypyrrole nanotubes.

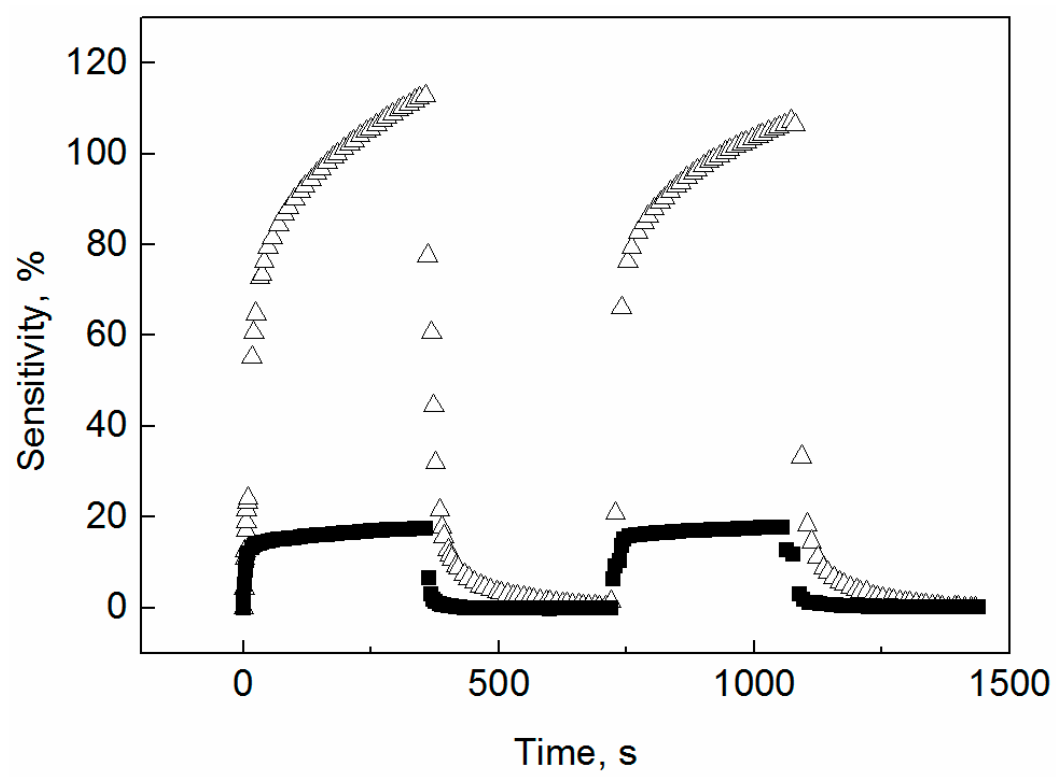

Figure 7. The response profile during two adsorption/desorption cycles in the presence of $n$-heptane $(6.0 \mathrm{vol} \%)$ for $(\triangle)$ polypyrrole nanotubes and $(\mathbf{\square})$ carbonized polypyrrole nanotubes. 
There is still one important trend observable (Figures 6 and 7), a significantly faster response of carbonized nanotubes on the change of the vapor environment especially in recovery process for both investigated solvents. This is probably due to structural changes during carbonization which are connected with increasing material porosity.

To determine the detection limit for ethanol and $n$-heptane, we can take into account a conventional definition that the minimum detectable signal (i.e., detection limit) of a sensor should be calculated as a value of input quantity which causes change of output quantity three times higher than it is the effective noise of output quantity. When evaluating the meta-data for Figures 6 and 7, we observed that the level of noise of sensor output is lower for carbonized polypyrrole nanotubes than for as-prepared polypyrrole nanotubes (this is a positive aspect of the former sensors). With respect to meta-data and the above-mentioned definition the detection limits were calculated as follows: 3000 ppm of ethanol on carbonized PPy nanotubes; 5000 ppm of ethanol on PPy nanotubes; and 10,000 ppm of $n$-heptane on carbonized PPy nanotubes; $5000 \mathrm{ppm}$ of $n$-heptane on PPy nanotubes.

A comparison of our sensitivity results with those found in the literature is included in Table 2. It is limited to detection of two relevant classes of compounds-alkanes and alcohols—on PPy nanotubes or their carbonized analogs. We have converted various expressions of sensitivity reported in original references to a quantity defined as the relative change in the resistivity, $S=\left(\Delta R / R_{0}\right) \times 100[\%]$.

Table 2. Overview of sensitivity of sensors based on PPy nanotubes, nitrogen-containing carbons, and MWCNT. The detected analytes are alkanes and alcohol vapors.

\begin{tabular}{|c|c|c|c|c|c|}
\hline \multirow{2}{*}{$\begin{array}{c}\text { Sensor Design } \\
\text { Sensitive Material }\end{array}$} & \multicolumn{5}{|c|}{ Detection Conditions } \\
\hline & Analyte & Concentration & $S(\%)$ & $\begin{array}{l}\text { Temp./Hum. } \\
\left({ }^{\circ} \mathrm{C}\right) /(\% \mathrm{RH})\end{array}$ & References \\
\hline \multicolumn{6}{|l|}{ Sensors of this work } \\
\hline PPy nanotubes & ethanol & \multirow{4}{*}{$\begin{array}{l}\text { saturated vapors } \\
\text { at } 25^{\circ} \mathrm{C}\end{array}$} & 18 & \multirow{4}{*}{$25 / 0$} & \multirow{4}{*}{ This work } \\
\hline deprotonated & n-heptane & & 110 & & \\
\hline \multirow{2}{*}{ PPy nanotubes carbonized } & ethanol & & 24 & & \\
\hline & n-heptane & & 20 & & \\
\hline \multicolumn{6}{|l|}{ Polypyrrole based sensors ${ }^{a}$} \\
\hline PPy/sulfate & propane/butane & $1040 \mathrm{ppm}$ & 55 & $27 / 35$ & [39] \\
\hline $\mathrm{PPy} / \mathrm{Cl}^{-}$ & $\begin{array}{l}\text { hexane } \\
\text { methanol }\end{array}$ & - & $\begin{array}{c}0.8 \\
5\end{array}$ & $100 / 0$ & [38] \\
\hline \multirow{4}{*}{$\mathrm{PPy} / \mathrm{ClO}_{4}^{-}$} & iso-butanol & \multirow{16}{*}{$\begin{array}{l}\text { saturated vapors } \\
\text { at } 25^{\circ} \mathrm{C}\end{array}$} & 15.5 & \multirow{16}{*}{$25 / 0$} & \multirow{16}{*}{ [15] } \\
\hline & ethanol & & 10.4 & & \\
\hline & iso-propanol & & 15.8 & & \\
\hline & $n$-pentanol & & 11.2 & & \\
\hline \multirow{4}{*}{$\mathrm{PPy} / \mathrm{PF}_{6}^{-}$} & iso-butanol & & 0.5 & & \\
\hline & ethanol & & 3.2 & & \\
\hline & iso-propanol & & 0.6 & & \\
\hline & n-pentanol & & 1.1 & & \\
\hline & iso-butanol & & 3.0 & & \\
\hline $\mathrm{PPy} / \mathrm{CF}_{2} \mathrm{SO}_{3}-$ & ethanol & & 7.5 & & \\
\hline 11 у $1 \mathrm{C}_{3} \mathrm{~s}_{3}$ & iso-propanol & & 4.4 & & \\
\hline & $n$-pentanol & & 1.3 & & \\
\hline \multirow{4}{*}{ PPy/camphorsulfonate } & iso-butanol & & 6.1 & & \\
\hline & ethanol & & 5.8 & & \\
\hline & iso-propanol & & 5.7 & & \\
\hline & $n$-pentanol & & 5.1 & & \\
\hline
\end{tabular}


Table 2. Cont.

\begin{tabular}{|c|c|c|c|c|c|}
\hline \multirow{2}{*}{$\begin{array}{c}\text { Sensor Design } \\
\text { Sensitive Material }\end{array}$} & \multicolumn{5}{|c|}{ Detection Conditions } \\
\hline & Analyte & Concentration & $S(\%)$ & $\begin{array}{l}\text { Temp./Hum. } \\
\left({ }^{\circ} \mathrm{C}\right) /(\% \text { RH })\end{array}$ & References \\
\hline \multirow{2}{*}{$\mathrm{PPy} / p$-toluenesulfonate } & methanol & \multirow{4}{*}{ - } & 18 & \multirow{4}{*}{-} & \multirow{4}{*}{ [40] } \\
\hline & ethanol & & 10 & & \\
\hline \multirow{2}{*}{ PPy/3-nitrobenzenesulfonate } & methanol & & 11 & & \\
\hline & ethanol & & 6 & & \\
\hline \multirow{4}{*}{$\begin{array}{l}\text { Nanostructured } \\
\mathrm{PPy} / \mathrm{ClO}_{4}^{-}\end{array}$} & methanol & \multirow{7}{*}{$\begin{array}{l}11 \% \text { wt. of VOC } \\
\text { in } n \text {-hexane }\end{array}$} & 2.9 & \multirow{7}{*}{$120 / 0$} & \multirow{7}{*}{ [41] } \\
\hline & ethanol & & 0.58 & & \\
\hline & n-propanol & & 0.22 & & \\
\hline & iso-propanol & & 0.18 & & \\
\hline \multirow{4}{*}{$\begin{array}{c}\text { Nanostructured } \\
\text { PPy } / p \text {-toluenesulfonate }\end{array}$} & methanol & & 1.5 & & \\
\hline & ethanol & & 0.75 & & \\
\hline & $n$-propanol & & - & & \\
\hline & iso-propanol & & - & & \\
\hline $\mathrm{PPy}_{\mathrm{P}} / \mathrm{PC}$ a & methanol & - & 7 & $-/ 0$ & \multirow{10}{*}{ [42] } \\
\hline PРy/PCPа & ethanol & & 7 & & \\
\hline PPy/PFO & methanol & & 3.5 & & \\
\hline PPY/PEU & ethanol & & 5.5 & & \\
\hline \multirow{2}{*}{ PРy/PMMA } & methanol & & 65 & & \\
\hline & ethanol & & 20 & & \\
\hline \multirow{2}{*}{ PPy/PVAL } & methanol & & 14 & & \\
\hline & ethanol & & 14 & & \\
\hline \multirow{2}{*}{ PPy/PVAc } & methanol & & 27.5 & & \\
\hline & ethanol & & 37.5 & & \\
\hline \multicolumn{6}{|l|}{ CNT based sensors } \\
\hline \multirow{2}{*}{ MWCNT } & iso-pentane & \multirow{4}{*}{$\begin{array}{l}\text { saturated vapors } \\
\text { at } 25^{\circ} \mathrm{C}\end{array}$} & 20.3 & \multirow{4}{*}{$25 / 60$} & \multirow{4}{*}{ [3] } \\
\hline & methanol & & 13.6 & & \\
\hline \multirow{2}{*}{ MWCNT/PMMA } & iso-pentane & & 12.6 & & \\
\hline & methanol & & 14.7 & & \\
\hline \multirow{2}{*}{ MWCNT/PMMA } & methanol & \multirow{4}{*}{$\begin{array}{l}\text { saturated vapors } \\
\text { at } 25^{\circ} \mathrm{C}\end{array}$} & 429 & \multirow{4}{*}{$-/ 0$} & \multirow{4}{*}{ [4] } \\
\hline & hexane & & - & & \\
\hline Surface modified & methanol & & 4500 & & \\
\hline MWCNT/PMMA & hexane & & - & & \\
\hline \multirow{2}{*}{ MWCNT } & iso-pentane & \multirow{4}{*}{$\begin{array}{c}\text { saturated vapors } \\
\text { at } 25^{\circ} \mathrm{C}\end{array}$} & 20.6 & & \\
\hline & methanol & & 12.9 & $25 / 60$ & [5] \\
\hline Oxidized MUUCNT & iso-pentane & & 12.0 & & \\
\hline Oxidized MWCNT & methanol & & 46.6 & & \\
\hline
\end{tabular}

${ }^{a}$ Definition of abbreviations: PCP—-polycaprolactone, PEO-poly(ethylene oxide), PMMA—poly(methyl methacrylate), PVAL — poly(vinyl alcohol), PVAc — poly(vinyl acetate), MWCNT—multi-wall carbon nanotubes, CVD—chemical vapor deposition, VOC—volatile organic compounds.

For alkanes detected on PPy (Table 2), there is reported detection of $1040 \mathrm{ppm}$ of propane/butane with sensitivity $55 \%$ [39], and an unknown concentration of hexane with sensitivity $0.8 \%$ [38]. In the present case, it was $60,000 \mathrm{ppm}$ of $n$-heptane with sensitivity $110 \%$. As for alkanes detected on carbon nanotubes, only response to the saturated vapor is reported (i.e., $905,000 \mathrm{ppm}$ at $25^{\circ} \mathrm{C}$ ) of iso-pentane which yielded sensitivity of $20.3 \%, 12.6 \%, 20.6 \%$, and $12 \%$ at various conditions [3]. The present result is $60,000 \mathrm{ppm}$ of $n$-heptane with sensitivity of $20 \%$.

As for alcohol vapors detected on PPy, there are mainly responses reported to vapors saturated at $25^{\circ} \mathrm{C}$ (their concentration is in the order of $10,000-100,000 \mathrm{ppm}$ ) in dependence on the number of carbon 
atoms in the alcohol molecule. The sensitivity varies from $0.22 \%$ to $37.5 \%$ [15,38,40-42]. The present result is $18 \%$ for $77,000 \mathrm{ppm}$ of ethanol. As for alcohol vapors detected on carbon nanotubes-for saturated methanol vapor there was reported sensitivity from $12.9 \%$ to $46.6 \%$ [3,5] —one paper presents significantly higher sensitivity, i.e., $429 \%$ and $4500 \%$ for saturated methanol vapor [4], while the result of this study is $24 \%$ for 77,000 ppm of ethanol.

To conclude, the preliminary results related to detection of $n$-heptane are significantly better than the average of those reported elsewhere. When comparing the response to alcohol vapors, there is a wide range of sensitivities; and they should be assessed case-by-case. The values obtained in this study are approximately in the middle of interval of reported sensitivities $[3,5]$. The detection of both alkanes and alcohol vapors will be the subject of our further systematic research.

\section{Conclusions}

During the oxidation of pyrrole with iron(III) chloride, globular morphology of PPy is transformed to nanotubes by addition of methyl orange. PPy bases obtained after deprotonation convert to nitrogen-containing carbon by heating to $650{ }^{\circ} \mathrm{C}$ in inert atmosphere. The original morphology is preserved after carbonization. Conductivity of PPy was reduced after the conversion to bases as well as after subsequent carbonization. The conductivity of globular form becomes too low for the application in sensors. The nanotubular PPy base, however, was demonstrated to respond to ethanol or $n$-heptane vapors by the change in resistivity. The sensitivity of the original nanotubular base to $n$-heptane reached $110 \%$, which is a unique result, and even the carbonized analog maintained a $20 \%$ sensitivity. The recovery was faster in the carbonized PPy. Organic vapor may reduce the humidity in the samples and thus cause a consequent increase in the resistivity.

Acknowledgments: This work was supported by the Czech Science Foundation (14-10279S, 16-02787S). This research was also sponsored by NATO Public Diplomacy Division in the framework of "Science for Peace" (984597).

Author Contributions: Jitka Kopecká and Dušan Kopecký synthesized PPy nanotubes; Patrycja Bober prepared and characterized carbonized samples; Jan Prokeš measured electrical conductivities of all samples; Zuzana Morávková and Miroslava Trchová provided IR and Raman spectra; Miroslav Mrlík and Robert Olejník prepared sensors and measured sensitivities; Martin Vrňata discussed material properties and discussed and wrote the sensor part; Jaroslav Stejskal contributed to data evaluation and manuscript preparation.

Conflicts of Interest: The authors declare no conflict of interest. The founding sponsors had no role in the design of the study; in the collection, analyses, or interpretation of data; in the writing of the manuscript, and in the decision to publish the results.

\section{References}

1. Abraham, J.K.; Philip, B.; Witchurch, A.; Varadan, V.K.; Reddy, C.C. A compact wireless gas sensor using a carbon nanotube/PMMA thin film chemiresistor. Smart Mater. Struct. 2004, 13, 1045-1049. [CrossRef]

2. Llobet, E. Gas sensors using carbon nanomaterials: A review. Sens. Actuators B Chem. 2013, 179, $32-45$. [CrossRef]

3. Olejník, R.; Slobodian, P.; Říha, P.; Machovský, M. Increased sensitivity of multiwalled carbon nanotube network by PMMA functionalization to vapors with affine polarity. J. Appl. Polym. Sci. 2012, 126, 21-29. [CrossRef]

4. Philip, B.; Abraham, J.K.; Chandrasekhar, A.; Varadan, V.K. Carbon nanotube/PMMA composite thin films for gas-sensing applications. Smart Mater. Struct. 2003, 12, 935-939. [CrossRef]

5. Slobodian, P.; Ř́ha, P.; Lengalová, A.; Svoboda, P.; Sáha, P. Multi-wall carbon nanotube networks as potential resistive gas sensors for organic vapor detection. Carbon 2011, 49, 2499-2507. [CrossRef]

6. Su, P.G.; Ho, C.J.; Sun, Y.L.; Chen, I.C. A micromachined resistive-type humidity sensor with a composite material as sensitive film. Sens. Actuators B Chem. 2006, 113, 837-842. [CrossRef]

7. Su, P.G.; Huang, S.C. Electrical and humidity sensing properties of carbon nanotubes- $\mathrm{SiO}_{2}$-poly(2-acrylamido-2-methylpropane sulfonate) composite material. Sens. Actuators B Chem. 2006, 113, 142-149. [CrossRef] 
8. Goldoni, A.; Larciprete, R.; Petaccia, L.; Lizzit, S. Single-wall carbon nanotube interaction with gases: Sample contaminants and environmental monitoring. J. Am. Chem. Soc. 2003, 125, 11329-11333. [CrossRef] [PubMed]

9. Peng, S.; Cho, K.J. Ab initio study of doped carbon nanotube sensors. Nano Lett. 2003, 3, 513-517. [CrossRef]

10. Hirsch, A. Functionalization of single-walled carbon nanotubes. Angew. Chem. Int. Ed. 2002, 41, 1853-1859. [CrossRef]

11. Liu, P. Modifications of carbon nanotubes with polymers. Eur. Polym. J. 2005, 41, 2693-2703. [CrossRef]

12. Ramanathan, T.; Liu, H.; Brinson, L.C. Functionalized SWNT/polymer nanocomposites for dramatic property improvement. J. Polym. Sci. B Polym. Phys. 2005, 43, 2269-2279. [CrossRef]

13. Wang, C.C.; Guo, Z.X.; Fu, S.K.; Wu, W.; Zhu, D.B. Polymers containing fullerene or carbon nanotube structures. Prog. Polym. Sci. 2004, 29, 1079-1141. [CrossRef]

14. Yao, Z.L.; Braidy, N.; Botton, G.A.; Adronov, A. Polymerization from the surface of single-walled carbon nanotubes-Preparation and characterization of nanocomposites. J. Am. Chem. Soc. 2003, 125, 16015-16024. [CrossRef] [PubMed]

15. Posudievsky, O.Y.; Konoschuk, N.V.; Kukla, A.L.; Pavluchenko, A.S.; Shirshov, Y.M.; Pokhodenko, V.D. Comparative analysis of sensor responses of thin conducting polymer films to organic solvent vapors. Sens. Actuators B Chem. 2011, 151, 351-359. [CrossRef]

16. Vrňata, M.; Kopecký, D.; Vysloužil, F.; Myslík, V.; Fitl, P.; Ekrt, O.; Hofmann, J.; Kučera, L. Impedance properties of polypyrrolic sensors prepared by MAPLE technology. Sens. Actuators B Chem. 2009, 137, 88-93. [CrossRef]

17. Ma, Y.W.; Zhang, L.R.; Li, J.J.; Ni, H.T.; Li, M.; Zhang, J.L.; Feng, X.M.; Fan, Q.L.; Hu, Z.; Huang, W. Carbon-nitrogen/graphene composite as metal-free electrocatalyst for the oxygen reduction reaction. Chin. Sci. Bull. 2011, 56, 3583-3589. [CrossRef]

18. Qie, L.; Chen, W.M.; Wang, Z.H.; Shao, Q.G.; Li, X.; Yuan, L.X.; Hu, X.L.; Zhang, W.X.; Huang, Y.H. Nitrogen-doped porous carbon nanofiber webs as anodes for lithium ion batteries with a superhigh capacity and rate capability. Adv. Mater. 2012, 24, 2047-2050. [CrossRef] [PubMed]

19. Xu, G.Y.; Ding, B.; Nie, P.; Shen, L.F.; Wang, J.; Zhang, X.G. Porous nitrogen-doped carbon nanotubes derived from tubular polypyrrole for energy-storage applications. Chem. Eur. J. 2013, 19, 12306-12312. [CrossRef] [PubMed]

20. Ćirić-Marjanović, G.; Pašti, I.; Gavrilov, N.; Janošević, A.; Mentus, S. Carbonised polyaniline and polypyrrole: Towards advanced nitrogen-containing carbon materials. Chem. Pap. 2013, 67, 781-813. [CrossRef]

21. Omastová, M.; Trchová, M.; Kovářová, J.; Stejskal, J. Synthesis and structural study of polypyrroles prepared in the presence of surfactants. Synth. Met. 2003, 138, 447-455. [CrossRef]

22. Stejskal, J.; Omastová, M.; Fedorová, S.; Prokeš, J.; Trchová, M. Polyaniline and polypyrrole prepared in the presence of surfactants: A comparative conductivity study. Polymer 2003, 44, 1353-1358. [CrossRef]

23. Blínová, N.V.; Stejskal, J.; Trchová, M.; Prokeš, J.; Omastová, M. Polyaniline and polypyrrole: A comparative study of the preparation. Eur. Polym. J. 2007, 43, 2331-2341. [CrossRef]

24. Peng, Y.J.; Qiu, L.H.; Pan, C.T.; Wang, C.C.; Shang, S.M.; Yan, F. Facile preparation of water dispersible polypyrrole nanotube-supported silver nanoparticles for hydrogen peroxide reduction and surface-enhanced Raman scattering. Electrochim. Acta 2012, 75, 399-405. [CrossRef]

25. Shang, S.M.; Yang, X.M.; Tao, X.M. Easy synthesis of carbon nanotubes with polypyrrole nanotubes as the carbon precursor. Polymer 2009, 50, 2815-2818. [CrossRef]

26. Škodová, J.; Kopecký, D.; Vrňata, M.; Varga, M.; Prokeš, J.; Cieslar, M.; Bober, P.; Stejskal, J. Polypyrrole-silver composites prepared by the reduction of silver ions with polypyrrole nanotubes. Polym. Chem. 2013, 4, 3610-3616. [CrossRef]

27. Yang, X.M.; Li, L.; Yan, F. Fabrication of polypyrrole/Ag composite nanotubes via in situ reduction of $\mathrm{AgNO}_{3}$ on polypyrrole nanotubes. Chem. Lett. 2010, 39, 118-119. [CrossRef]

28. Yang, X.M.; Li, L.; Yan, F. Polypyrrole/silver composite nanotubes for gas sensors. Sens. Actuators B Chem. 2010, 145, 495-500. [CrossRef]

29. Yang, X.M.; Li, L.A.; Zhao, Y. Ag/AgCl-decorated polypyrrole nanotubes and their sensory properties. Synth. Met. 2010, 160, 1822-1825. [CrossRef] 
30. Stejskal, J.; Trchová, M.; Bober, P.; Morávková, Z.; Kopecký, D.; Vrňata, M.; Prokeš, J.; Varga, M.; Watzlová, E. Polypyrrole salts and bases: Superior conductivity of nanotubes and their stability towards the loss of conductivity by deprotonation. RSC Adv. 2016, 6, 88382-88391. [CrossRef]

31. Kudoh, Y. Properties of polypyrrole prepared by chemical polymerization using aqueous solutions containing $\mathrm{Fe}_{2}\left(\mathrm{SO}_{4}\right)_{3}$ and anionic surfactants. Synth. Met. 1996, 79, 17-22. [CrossRef]

32. Omastová, M.; Pionteck, J.; Trchová, M. Properties and morphology of polypyrrole containing a surfactant. Synth. Met. 2003, 135, 437-438. [CrossRef]

33. Mrlík, M.; Pavlínek, V.; Cheng, Q.L.; Sáha, P. Synthesis of titanate/polypyrrole composite rod-like particles and the role of conducting polymer on electrorheological efficiency. Int. J. Mod. Phys. B 2012, 26, 280-286. [CrossRef]

34. Quadrat, O.; Stejskal, J. Polyaniline in electrorheology. J. Ind. Eng. Chem. 2006, 12, 352-361.

35. Sedlačík, M.; Mrlík, M.; Pavlínek, V.; Sáha, P.; Quadrat, O. Electrorheological properties of suspensions of hollow globular titanium oxide/polypyrrole particles. Colloid Polym. Sci. 2012, 290, 41-48. [CrossRef]

36. Kostić, R.; Raković, D.; Stepanyan, S.A.; Davidova, I.E.; Gribov, L.A. Vibrational Spectroscopy of Polypyrrole, Theoretical-Study. J. Chem. Phys. 1995, 102, 3104-3109. [CrossRef]

37. Dresselhaus, M.S.; Jorio, A.; Hofmann, M.; Dresselhaus, G.; Saito, R. Perspectives on carbon nanotubes and graphene Raman spectroscopy. Nano Lett. 2010, 10, 751-758. [CrossRef] [PubMed]

38. Pirsa, S.; Alizadeh, N. Design and fabrication of gas sensor based on nanostructure conductive polypyrrole for determination of volatile organic solvents. Sens. Actuators B Chem. 2010, 147, 461-466. [CrossRef]

39. Bulakhe, R.N.; Patil, S.V.; Deshmukh, P.R.; Shinde, N.M.; Lokhande, C.D. Fabrication and performance of polypyrrole (Ppy) $/ \mathrm{TiO}_{2}$ heterojunction for room temperature operated LPG sensor. Sens. Actuators B Chem. 2013, 181, 417-423. [CrossRef]

40. De Souza, J.E.G.; dos Santos, F.L.; Barros-Neto, B.; dos Santos, C.G.; de Melo, C.P. Polypyrrole thin films gas sensors. Synth. Met. 2001, 119, 383-384. [CrossRef]

41. Babaei, M.; Alizadeh, N. Methanol selective gas sensor based on nano-structured conducting polypyrrole prepared by electrochemically on interdigital electrodes for biodiesel analysis. Sens. Actuators B Chem. 2013, 183, 617-626. [CrossRef]

42. De Melo, C.P.; Neto, B.B.; de Lima, E.G.; de Lira, L.F.B.; de Souza, J.E.G. Use of conducting polypyrrole blends as gas sensors. Sens. Actuators B Chem. 2005, 109, 348-354. [CrossRef]

(C) 2016 by the authors; licensee MDPI, Basel, Switzerland. This article is an open access article distributed under the terms and conditions of the Creative Commons Attribution (CC-BY) license (http://creativecommons.org/licenses/by/4.0/). 